\title{
Features of Pathobiology and Clinical Translation of Approved Treatments for Coronavirus Disease 2019
}

\author{
Ali Fallah ${ }^{a}$ Hadi Razavi Nikoo b,c Hamidreza Abbasi ${ }^{d}$ \\ Azadeh Mohammad-Hasani ${ }^{\mathrm{e}}$ Abasalt Hosseinzadeh Colagar ${ }^{\mathrm{a}}$ \\ Ayyoob Khosravie,f \\ aDepartment of Molecular and Cell Biology, Faculty of Basic Science, University of Mazandaran, Babolsar, Iran; \\ ${ }^{b}$ Infectious Disease Research Centre, Golestan University of Medical Sciences, Gorgan, Iran; 'Department of

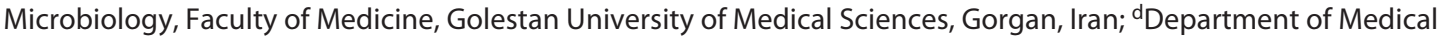 \\ Biotechnology, Faculty of Advanced Medical Technologies, Golestan University of Medical Sciences, Gorgan, Iran; \\ eDepartment of Molecular Medicine, Faculty of Advanced Medical Technologies, Golestan University of Medical \\ Sciences, Gorgan, Iran; 'Stem Cell Research Centre, Golestan University of Medical Sciences, Gorgan, Iran
}

\section{Keywords}

SARS-CoV-2 · COVID-19 · Genome organization · Pathogenic mechanisms

\begin{abstract}
Background: Severe acute respiratory syndrome coronavirus-2 (SARS-CoV-2) is currently the most important etiological agent of acute respiratory distress syndrome (ARDS) with millions of infections and deaths in the last 2 years worldwide. Several reasons and parameters are responsible for the difficult management of coronavirus disease-2019 (COVID-19) patients; the first is virus behavioral factors such as high transmission rate, and the different molecular and cellular mechanisms of pathogenesis remain a matter of controversy, which is another factor. Summary: In the present review, we attempted to explain about features of SARSCOV-2, particularly focusing on the various aspects of pathogenesis and treatment strategies. Key Messages: We note evidence for the understanding of the precise molecular and
\end{abstract}

karger@karger.com www.karger.com/int

Karger $\frac{1}{\%}$

GOPEN ACCESS
(C) 2021 The Author(s)

Published by S. Karger AG, Basel

This is an Open Access article licensed under the Creative Commons Attribution-NonCommercial-4.0 International License (CC BY-NC) (http://www.karger.com/Services/OpenAccessLicense), applicable to the online version of the article only. Usage and distribution for commercial purposes requires written permission. cellular mechanisms of SARS-CoV-2 pathogenesis, which can help design the appropriate drug or vaccine. Additionally, and importantly, we reported the updated issues associated with the history and development of treatment strategies such as, drugs, vaccines, and other medications that have been approved or under consideration in clinics and markets worldwide.

(c) 2021 The Author(s)

Published by S. Karger AG, Basel

\section{Introduction}

The novel coronavirus-infected persons from $\mathrm{Wu}$ han city, Hubei Province, China, were described in December 2019 [1]. To date, the acute respiratory distress syndrome (ARDS) related to novel coronavirus affected

Ali Fallaha, Hadi Razavi Nikoob and Hamidreza Abbasid contributed equally.
Correspondence to:

Abasalt Hosseinzadeh Colagar, ahcolagar@umz.ac.ir

Ayyoob Khosravi, ayyoobfarsian@yahoo.com 
$>200$ countries, with millions of confirmed cases and deaths [2]. The coronavirus that was named as the severe acute respiratory syndrome coronavirus-2 (SARS$\mathrm{CoV}-2$ ), and other human coronaviruses including OC43 (HCoV-OC43), human coronavirus HKU1, severe acute respiratory syndrome coronavirus-1 (SARSCoV-1), and Middle East respiratory syndrome-related coronavirus (MERS-CoV) belong to the genus Beta coronaviruses [3, 4]. SARS-CoV-2 has high homology to bat coronavirus ( $89 \%)$, and SARS-CoV-1 (80\%), which indicate have common ancestry with viruses found in bats, and recombination occurred in intermediated hosts including Pangolin. However, there is not yet strong evidence for an intermediate host. The reproduction number (R0) of SARS-CoV-2 was estimated to be $2.24-3.58$, which is higher than that of MERS $(\mathrm{R} 0=1)$ and lower than that of SARS-CoV-1 (R0 value of 2-5). Besides, the case fatality rate of SARS-CoV-2 is lower (3.4\%) than that of SARS-CoV-1 (9.6\%) and MERS $(35 \%)$, and the incubation period of these viruses was found to be $1-14$ days, with an average of 5 days $[5,6]$. Clinical manifestation of different coronavirus is variable from the common cold to severe respiratory diseases, with high fever, cough, and multiple system dysfunction. The disease caused by SARS-CoV-2 is known as coronavirus disease 19 (COVID-19) [7]. The mechanism of SARS-CoV-2-induced pathophysiology is a multifactorial process, and is not fully understood. Advances in the prevention and effective management of COVID-19 will require detailed knowledge about SARSCOV-2 pathogenesis [8]. The present study was performed to identify and evaluate the available data on different molecular and cellular mechanisms involved in SARS-COV-2 pathogenesis that may be useful in the design of appropriate drugs or vaccines.

\section{SARS-CoV-2 Features (Morphology, Genome Organization, and Its Proteins)}

SARS-CoV-2 includes pleomorphic spherical particles of 70-90 nm diameter with coronavirus-specific morphology that were derived from clinical samples and seen under a transmission electron microscope $[9,10]$. Coronaviruses are enveloped viruses containing an unsegmented, single-stranded, positive-sense RNA genome of around $30 \mathrm{~kb}$ in length, which is enclosed by a $5^{\prime}$-cap and $3^{\prime}$-poly (A) tail $[10,11]$. The genome organization of SARS-CoV-2 has similarities to that of other beta-coronaviruses. SARS-CoV-2 genome is demarcated by short
RNA breakpoint sequences that lead to recombination at specific nonrandom locations within the viral genome, suggesting the evolutionary pattern of coronaviruses over vast distances in time [12].

The genome and subgenome produce 6 open reading frames (ORFs). The majority of the $5^{\prime}$ end is occupied by ORF1a/b, encoding sixteen nonstructural proteins (NSP1-NSP16) [11, 13]. One large polyprotein is initially produced from ORF1a/b and cleaved by the papain-like protease encoded within NSP3 and the 3C-like protease, to produce replication-transcription complex, which are necessary for viral transcription and replication. The remaining ORFs encode for 9 putative accessory proteins and 4 structural proteins (Spike-S, Envelope-E, Membrane-M, and Nucleocapsid-N) (Fig. 1) [14]. The specific role and function of each protein in the life cycle of the virus are shown in Table 1. Phylogenetic analysis of the SARS-CoV-2 S gene sequence illustrates that there are distinguished 27 amino acid substitutes in contrast to SARS-CoV-1/SARS-like coronaviruses. These substitutions are about higher infectivity and lower pathogenicity of SARS-CoV-2 than SARS-like coronaviruses [15]. SARS-CoV-2 evolved 2 major types $L$ and $S$ that differ in 2 SNPs. These are at positions of 8782 and 28114 that are located in ORF1ab (T8517C, synonymous) and ORF8 (C251T, S84L), respectively [16]. In addition, L type was the most prevalent, detected in $70 \%$ of the samples amplified, and S type was detected in $30 \%$ of the specimens. L and S types of SARS-CoV-2 have very small genetic differences and may not influence the immune response [4].

Four major structural proteins in SARS-CoV-2 are mentioned in brief below:

(1) $\mathrm{S}$ is a large multifunctional transmembrane glycoprotein, and cleaved into S1 and S2 units. (2) Matrix glycoprotein $(\mathrm{M})$ is the most abundant viral protein, which gave a definite shape to the viral envelope, and is essential for virus morphogenesis and assembly. (3) E is the smallest of the major structural proteins. It acts as a viroporin (ion channel) and is essential for various stages of the virus cycle, such as pathogenesis, assembly, and release of the virus. (4) $\mathrm{N}$ is the only structural protein that binds to the genomic RNA, and facilitates virion assembly, and enhances the transcription efficiency of the virus [17-20].

\section{SARS-CoV-2 Pathobiology and Treatment Options}

\section{Binding to ACE2 and Entry}

The first SARS-CoV-2 targets human cells, such as nasal and bronchial epithelial cells and pneumocystis, 


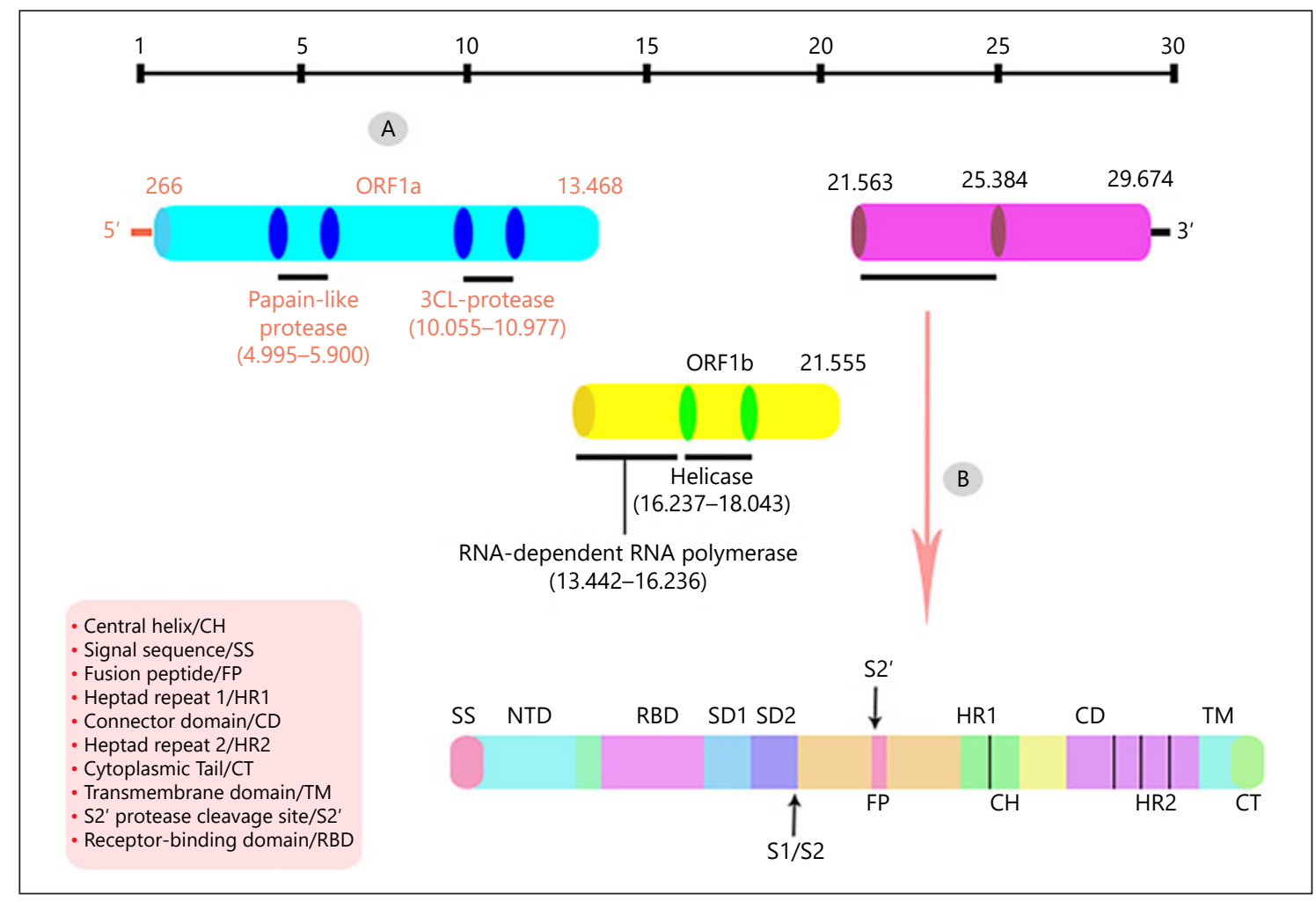

Fig. 1. Genome properties of SARS-CoV-2. A The large replica polyproteins encoded by ORF $1 \mathrm{a} / \mathrm{b}$ are cleaved by the $\mathrm{PL}^{\text {pro }}$ and the $3 \mathrm{CL}^{\text {pro }}$, to produce nonstructural proteins that are highly conserved throughout coronaviruses. B The $S$ protein mainly contains

through the binding of viral structural $S$ glycoprotein to the angiotensin-converting enzyme 2 (ACE2), as a zinccontaining metalloenzyme, which is widely expressed in many cells [21]. The attachment of receptor-binding domain (RBD) located on the surface of $S$ glycoprotein to ACE2 prompts endocytosis of the virus [22]. The S1 subunit binds to the ACE2 via its RBD, and the $\mathrm{S} 2$ subunit is responsible for membrane fusion (Fig. 2) [3]. Additionally, the priming of the virus $S$ protein is mediated by different co-receptors and activators, including transmembrane serine protease 2 and endosomal/lysosomal cysteine proteases such as cathepsin B and L. Taken together, these events can cause downregulation of ACE2, through internalization and degradation of the protein, which in turn results in the loss of cilia and squamous metaplasia, which contribute to severe lung injury $[23,24]$. In addition to the ACE2 receptor, SARS-CoV-2 could bind the putative alternative receptor CD147 to enter target cells. Research has shown that when CD147 protein expression is inhibited, cell infection with the new coronavirus is reduced by $50 \%[5,25]$. the S1 and S2 subunits. The S1/S2 cleavage sites are highlighted. This scheme is a mixed conclusion from a previous study [15-20]. PL ${ }^{\text {pro, }}$, papain-like protease; 3CL ${ }^{\text {pro }}, 3 \mathrm{C}$-like protease; S, spike; ORF1a/b, open reading frame $1 \mathrm{a} / \mathrm{b}$; SARS-CoV-2, .

According to the WHO and COVID-19 treatment guidelines, many antiviral agents are known today as "effective compounds" against the SARS-CoV-2, but here we investigated the NIH- or WHO-recommended antiviral agents that are available at https://www.covid19treatmentguidelines.nih.gov [26] for a better understanding of their antiviral properties on SARS-CoV-2. These drugs can target viral replication machinery, RNA polymerase, and viral protease, or modulate inflammatory responses against SARS-CoV-2 [27, 28]. Characteristics of approved and under development therapeutics options such as medication class, product name, clinical phase, manufacturing, mechanisms of action, dosage, and limitation are shown in Table 2 and Figure 3.

Reduction of viral loads in COVID-19 patients treated with some antiviral agents that can inhibit the binding of SARS-CoV-2 to host cells was found in various phases of clinical trials, indicating the inhibitory effect of these molecules on viral envelope proteins and their host cell receptors/co-receptors $[31,32]$. These are including antiviral drugs (ivermectin), neutralizing monoclonal anti- 
Table 1. Function of nonstructural and structural proteins of SARS-CoV-2

\begin{tabular}{|c|c|}
\hline Protein name & Function \\
\hline NSP1 (N-terminal product of the viral replicase) & Inhibition of host translation machinery and innate immune response (virulent factor) \\
\hline NSP2 (N-terminal product) & Binds to PHBs 1, 2 (prohibitin), supposed role in apoptosis induction \\
\hline NSP3 (papain-like proteinase) & Release NSPs 1, 2, and 3 from the N-terminal region of pp1a and $1 \mathrm{ab}$ \\
\hline NSP4 (double-membrane vesicle maker) & Viral RTC and membrane rearrangement \\
\hline NSP5 (main proteinase or 3CLpro) & Cleaves at multiple distinct sites of NSP polyprotein \\
\hline NSP6 (putative transmembrane domain) & Induces the formation of autophagosomes \\
\hline NSP7 (RNA-dependent RNA polymerase) & Part of the RTC, and forms complex with NSP8 and 12 \\
\hline NSP8 (multimeric RNA polymerase; replicas) & Part of the RTC, and forms heterodimer with NSP8 and 12 \\
\hline NSP9 (RNA-binding protein) & May bind to helicase \\
\hline $\begin{array}{l}\text { NSP10 (growth-factor-like protein possessing } 2 \text { zinc binding } \\
\text { motifs) }\end{array}$ & Modulates NSP16, as a methyltransferase stimulator \\
\hline NSP11 & Unknown (consists of 13 amino acids and identical to the first segment of Nsp12) \\
\hline NSP12 (RNA-dependent RNA polymerase) & Part of the RTC, and copies viral RNA and methylation (guanine) \\
\hline NSP13 (RNA helicase) & $\begin{array}{l}\text { Unwinds duplex RNA (helicase), part of the RNA polymerase complex, involved in virus } \\
\text { replication }\end{array}$ \\
\hline NSP14 (proofreading exonuclease) & $\begin{array}{l}\text { Proofreading of the viral genome, which prevents lethal mutagenesis and functions as a } \\
\text { methyltransferase for mRNA capping }\end{array}$ \\
\hline NSP15 (RNA endonuclease) & Degrade RNA to hide from host defense \\
\hline NSP16 (2 0 -O-ribose methyltransferase) & 5'-cap RNA methylation \\
\hline ORF3a & $\begin{array}{l}\text { Interactions with some structural proteins and involved in virus release, apoptosis, and } \\
\text { pathogenesis }\end{array}$ \\
\hline ORF3b & Apoptosis stimulator, and inhibits the antiviral innate immune response \\
\hline ORF6 & Effective in viral pathogenesis, and inhibition of IFN induction \\
\hline ORF7a & Apoptosis induction \\
\hline ORF7b & Unknown (an integral membrane protein, expressed in viral-infected cells) \\
\hline ORF8 & May enhance replication and shows interaction with some structural proteins \\
\hline ORF9b & Shows interaction with some NSPs and interferon antagonist \\
\hline ORF10 & Its function is not clearly understood but may have an immune modulatory role \\
\hline ORF14 & Unknown (consists of 73 amino acid residues) \\
\hline S protein & Mediates attachment and viral entry into the host cell \\
\hline E protein & $\begin{array}{l}\text { It acts as a viroporin and is essential for stages of the virus cycle, such as pathogenesis, } \\
\text { assembly, and release of the virus }\end{array}$ \\
\hline M protein & It is essential for virus morphogenesis and assembly \\
\hline N protein & It facilitates virion assembly and enhances the transcription efficiency of the virus \\
\hline
\end{tabular}

SARS-CoV-2, severe acute respiratory syndrome coronavirus-2; N, Nucleocapsid; M, Membrane; S, Spike; E, Envelope; ORF, open reading frame; NSPs, nonstructural proteins; RTC, replication-transcription complex. ${ }^{*}$ Concluded from previous studies [17-20].

bodies (bamlanivimab and etesevimab), recombinant human monoclonal antibodies (casirivimab, imdevimab, and sotrovimab), and convalescence plasma [33]. At the beginning of the pandemic, several studies reported data on the antiviral activity of ivermectin, hydroxychloroquine alone, or in combination with azithromycin against SARS-CoV-2 [34-36]. The updates obtained from different trials with thousands of COVID-19 patients indicated these drugs do not reduce mortality or the duration of mechanical ventilation, and even cause adverse drug reactions [37]. Convalescent plasma or serum from a patient who recovered from COVID-19 could be another option for prophylaxis of infection and treatment of COVID-19 patients, particularly after the onset of symptoms
[38]. The antibody binds the $S$ protein which prevents the entry of SARS-CoV-2 into the host cell and viral neutralization. In addition, the antibody modulates the inflammatory response, which is also more easily achieved during the initial immune response, a stage that may be asymptomatic [39]. There are reports that convalescent serum was used for the therapy of patients with $\mathrm{CO}$ VID-19 in China during the current outbreak [40]. Recently, the connection of the SARS-CoV-specific human MAb CR3022 to SARS-CoV-2 RBD showed its potential as a remedial factor in the management of SARS-CoV-2. Indeed, it can be applied alone or in combination with other impressive treatments [41]. 
Fig. 2. The $S$ protein of coronaviruses facilitates viral entry into target cells. The $S$ protein of SARS-CoV-2 binds to ACE2 as the entry receptor, through its S2 subunit for viral attachment. The $S$ protein is cleaved by the cellular serine protease that called TMPRSSs at the S1/S2 boundary or within the S1 subunit, which removes the structural constraint of S1 on S2, and releases the internal fusion peptide combined with the S TM domain for the viral fusion. This scheme is a mixed conclusion from a previous study [24]. S, spike; SARS-CoV-2, severe acute respiratory syndrome coronavirus-2; ACE2, angiotensin-converting enzyme 2;TMPRSSs, transmembrane serine proteases.

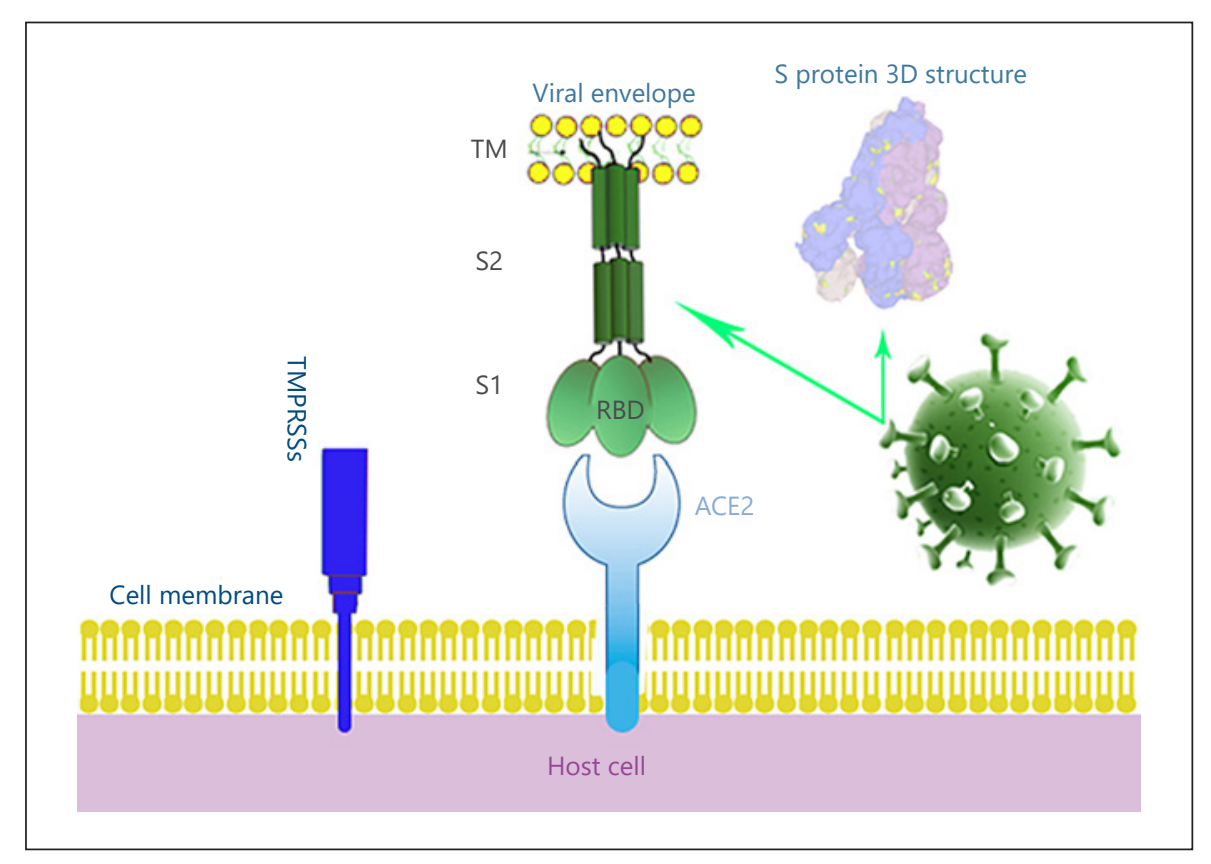

\section{Translation and Replication}

After the attachment, the ACE2/S SARS-CoV-2 complex is internalized into the cytoplasm by receptor-mediated endocytosis and prompts uncoating of virion in the acidic endosomal vesicles to release of the single-stranded viral RNA [42]. The positive single-stranded viral RNA translated into replicase polyproteins $\mathrm{pp} 1 \mathrm{a} / \mathrm{pp} 1 \mathrm{~b}$ and other products such as nsp1-16 collectively constitute the functional replication-transcription complexes by the host cell machinery [43]. Ribosomal frame shifting during the translation process has been seen in the replication of SARS-CoV-2, which produces genomic and multiple copies of subgenomic RNA species [23, 44]. The assembly of viral particles takes place via the interaction of genomic RNA and viral envelope proteins (S, E, and $\mathrm{M}$ ) at the endoplasmic reticulum and Golgi complex [45]. Finally, these virions are subsequently released out of the cells via exocytosis [46]. It has been shown that several antiviral drugs influence the viral replication machinery in different ways: (i) directly targeting the viral proteins, such as RdRp and viral protease, and (ii) interruption of viral replication machinery through modulating cellular factors $[47,48]$. Remdesivir, favipiravir, ribavirin, sofosbuvir, and tenofovir revealed the interaction and inhibition of RdRp, resulting in the reduced viral RNA synthesis and mRNA capping [49]. Remdesivir is the best example of a novel nucleotide analog with strong therapeutic applications against a diverse range of human viruses such as Ebola virus disease, SARS-CoV-1 and MERS, and SARS-like coro- naviruses that inhibit viral RNA synthesis [50]. In addition, other inhibitors including lopinavir, ritonavir (Kaletra), and darunavir have been tested in clinical trials in the treatment of COVID-19 patients. This class of drugs interferes with the processing of the viral polyprotein by blocking the function of viral protease. Among these drugs, remdesivir is the only FDA-approved antiviral agent for the treatment of COVID-19 [51].

\section{Inflammatory Responses}

Virus replication (Viral phase) in pneumocytes leads to the inflammatory response, including macrophages, natural killer cells, CD4+T cells, cytotoxic T lymphocytes/CTLs, and antibody responses [52]. In later stages of infection, epithelial-endothelial barrier integrity is compromised, which potentially mediates lung injury, as well as extrapulmonary systemic involvement caused by SARS-CoV-2 [53]. Viral replication and pathobiology of SARS-CoV-2 virus are shown in Figure 4A-D. Several therapeutics plans modulate inflammatory responses against SARS-CoV-2 by different mechanisms. Approved and under evaluation plans include (1) immunomodulatory (colchicine, corticosteroids, interleukin inhibitors [IL-1 and IL-6], and interferons) and (2) cell-based therapy (mesenchymal stem cell) [54-56].

\section{Pathology}

Pathophysiology of SARS-CoV-2-induced ARDS is a multifactorial process and is very similar to SARS-CoV-1 


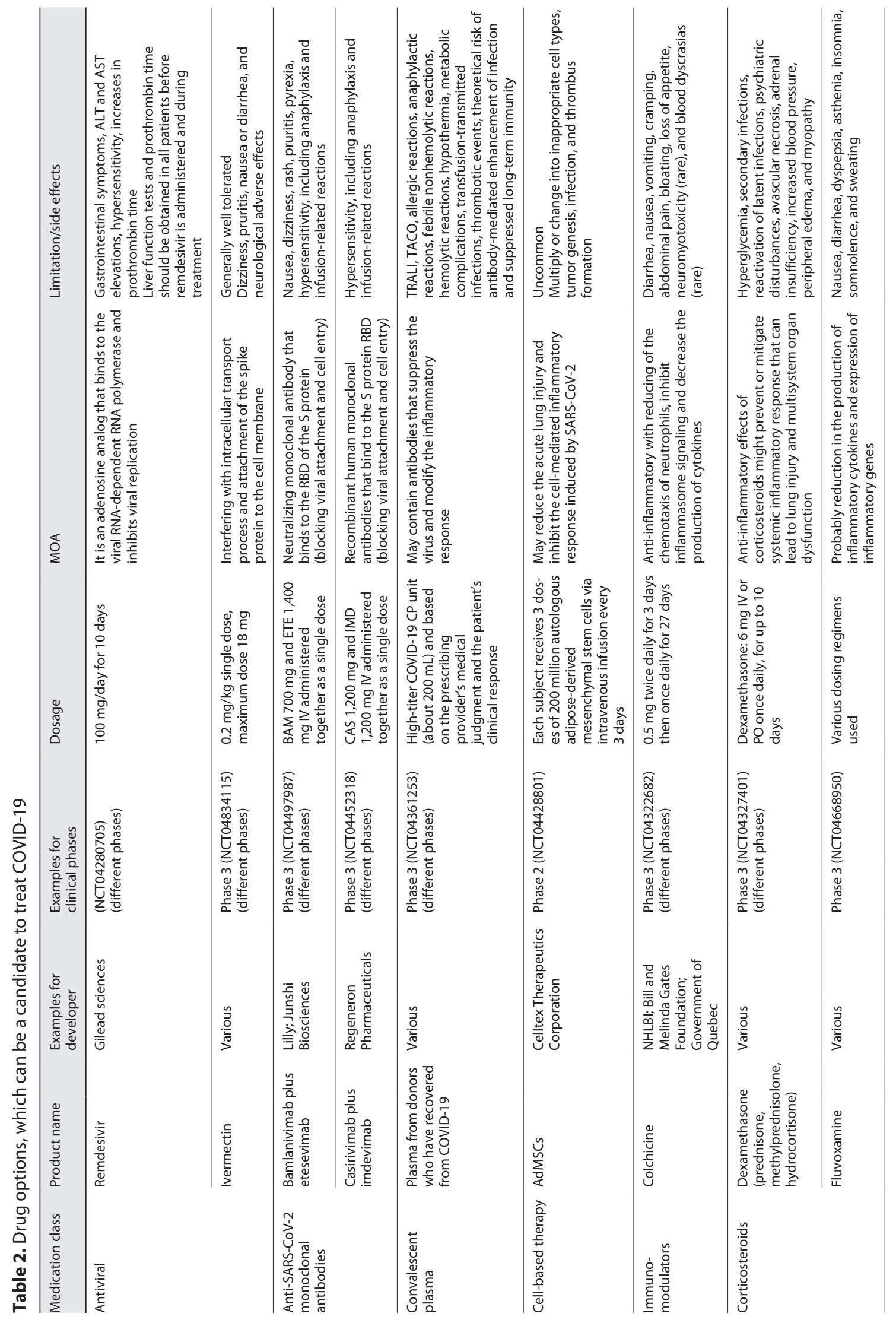




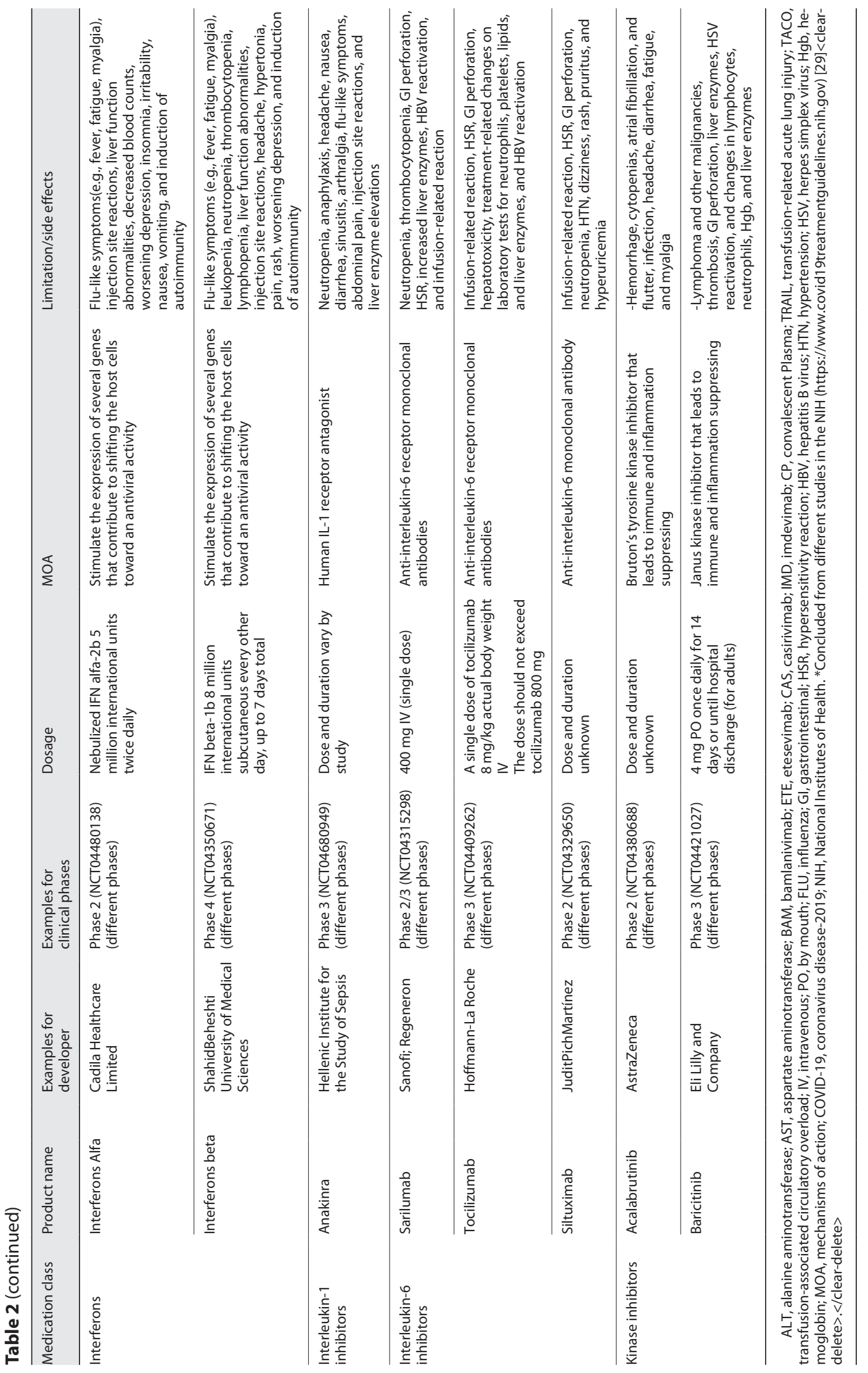




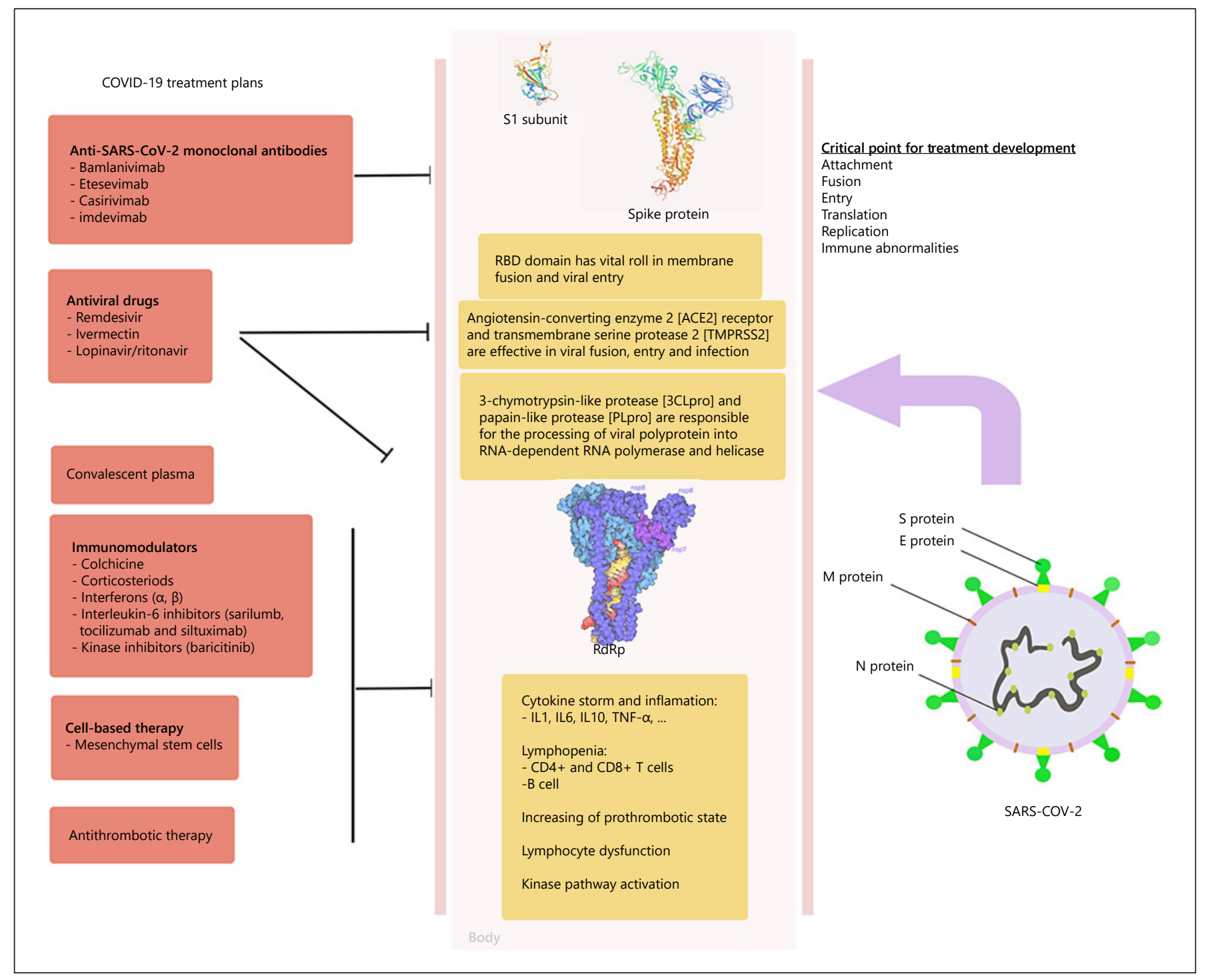

Fig. 3. Featured and critical data for approved and under development of therapeutics plans. These plans can treat COVID-19 patients in various stages such as attachment, entry, replication and hyper inflammation phase [80]. COVID-19, coronavirus disease 19 ; RBD, receptor-binding domain; SARS-CoV-2, severe acute re-

Fig. 4. Molecular and cellular mechanisms of SARS-CoV-2 pathogenesis, from air to the blood: SARS-CoV-2 adjusted to alveoli epithelial cell (A); the infection cycle of the SARS-CoV-2 starts with the binding of the virion to the receptor ACE2 via receptormediated endocytosis and its proliferation (B); immune responses to SARS-CoV-2 including (C) (1) macrophages that efficiently capture and kill viruses, and produce NO and cytokines; (2) NK cells that secrete cytokines and kill infected host cells that fail to express sufficient peptide-MHC class I and infected DCs; (3) CD4+ T cells, which reciprocally license DCs for T-cell activation; (4) CTLs that kill virus-infected host cells by death ligands (FAS/ FASL) and by cytokines or perforin/granzyme; (5) neutralizing an- spiratory syndrome coronavirus-2; S, spike; ACE2, angiotensinconverting enzyme 2; TMPRSS2, transmembrane serine protease 2; 3CLpro, 3C-like protease; PLpro, papain-like protease; M, Membrane; N, Nucleocapsid; E, Envelope.

tibody production that bounds to the virus and engaged FcRs on an NK cell, macrophage, or neutrophil that triggers the ADCC. On the other hand, these antibodies can bind to the complement component $\mathrm{C} 1$, resulting in the activation of MAC and destruction of the infected cell. Another complement component such as free C3b binds to the virus surface and mediated phagocytosis by neutrophil CR1 receptors. D The viral spread to the cardiovascular system. NK cells, natural killer cells; DCs, dendritic cells; CTLs, cytotoxic T lymphocytes; ADCC, antibody-dependent cellular cytotoxicity; MAC, membrane attack complex; SARS-CoV-2, severe acute respiratory syndrome coronavirus-2; ACE2, angiotensinconverting enzyme 2.
(For figure see next page.) 


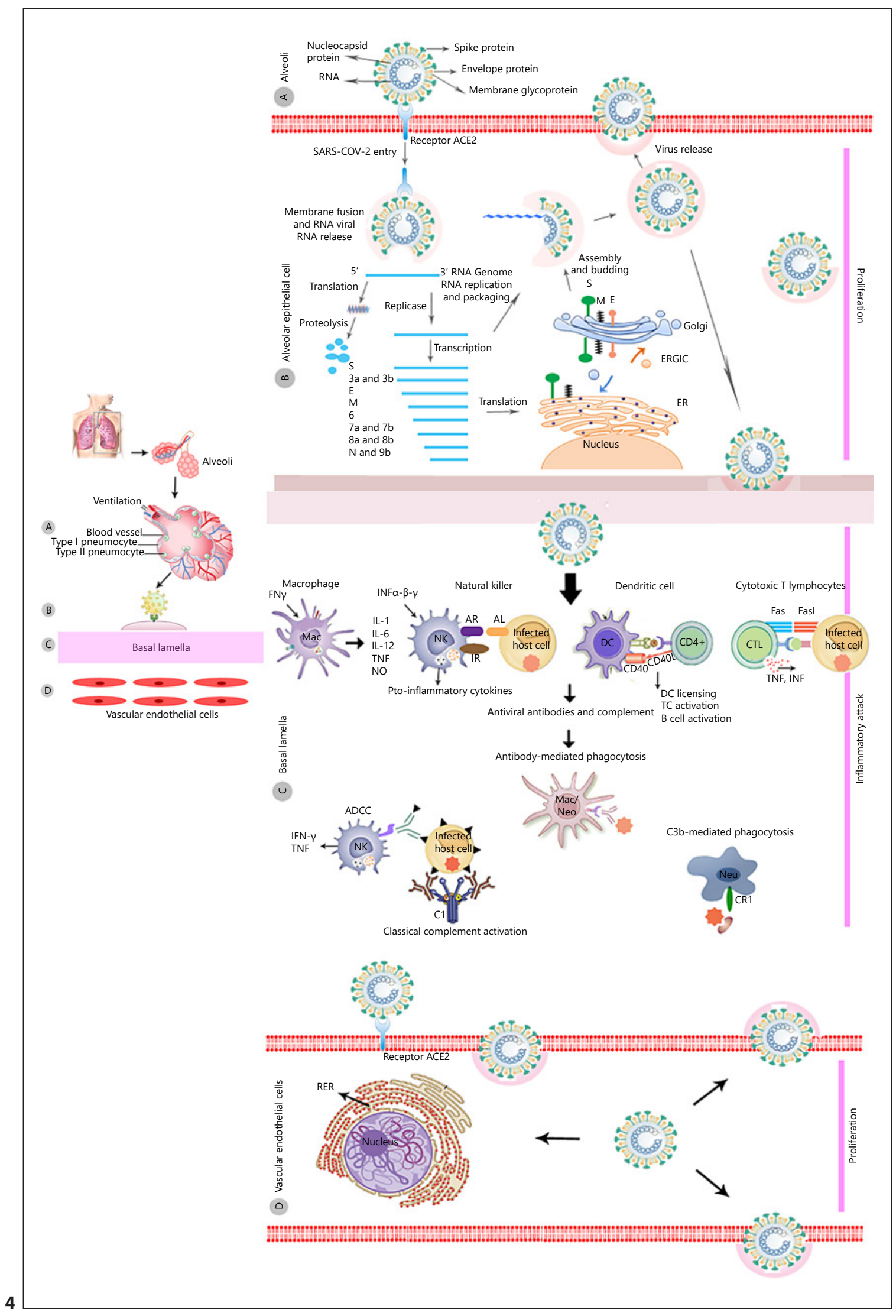


and MERS infectious patients, with less severe pathogenesis $[57,58]$. The clinical symptoms of SARS-CoV-2 can be asymptomatic, symptomatic, mild, and also lead to severe disease with multi-organ failure. In the symptomatic phase or Viral phase, in which the clinical manifestations of the disease usually start 5 days after exposure, patients may experience symptoms such as fever, dyspnea, sore throat, chest pain, expectoration, cough, and myalgia, but fever, cough, and fatigue are common symptoms of COVID-19 [59]. At the present, there are different confirming diagnostic methods for the detection of SARS-CoV-2 in patients, around the time of symptom onset, in laboratories, as follows: (1) nucleic acid tests like real-time RT-PCR or next-generation sequencing; (2) antibody or antigen detection tests, including enzymelinked immunosorbent assay; (3) chest computed tomography and spectroscopic techniques [60-63]. Real-time RT-PCR on nasopharyngeal and oropharyngeal swabs is considered the "gold standard" for confirming the diagnosis in clinical cases of COVID-19 [64, 65]. Besides clinical symptoms, the blood biochemistry indexes such as the total white blood cell, lymphocyte, platelet, and thromboplastin time decline, while C-reactive protein, lactate dehydrogenase, aspartate transaminase, alanine aminotransferase, cytokine level, and bilirubin increase in most patients [66]. ARDS is a prevalent phenomenon in patients, followed by anemia, acute heart injury, and secondary infections [67]. Reports illustrate that middleaged and older people with chronic and underlying diseases, especially high blood pressure and diabetes, are susceptible to respiratory failure and have poorer prognoses, but it does not mean that children are lesser than old people susceptible to SARS-CoV-2 [68-70]. In the later stages of infection or the thrombo-inflammatory phase, ARDS is a common complication, and resulted from the occurrence of cytokine storms and immune regulatory network imbalance, which is finally followed by anemia, acute heart damage, multiple organ failure, and secondary bacterial infections [71]. Bilateral severe interstitial inflammation of the lungs is found in the chest computed tomography pictures or chest X-ray, which is named ground-glass opacity and involves a local lobe but later expands to multiple lung lobes [67].

\section{Vaccines}

With the threat of millions of people being infected and health-care systems becoming overwhelmed, the race is on to develop a vaccine that will protect individuals and slow the spread of the disease [72]. S protein plays a significant role in the induction of protective immunity against SARS-CoV-2 by mediating T-cell responses and neutralizing antibody production [73]. In the past few decades, scientists would develop vaccines that induce the body to produce antibodies that recognize and block human coronaviruses with the use of $\mathrm{S}$ protein as the target [74]. Nonetheless, the expanded vaccines have minimal usage, even between strains close together of the virus, owing to an absence of cross-conservation [75]. Recently, researchers identified the at least target domain of the virus's S protein that is critical for docking with ACE2 receptor and this region or RBD located in the S1 subunit of the $S$ protein [76-78]. Furthermore, several studies strongly reported that viral structural proteins such as $\mathrm{N}$, $\mathrm{M}$, and $\mathrm{E}$ proteins have the potential for inclusion within future vaccine candidates to stimulate $\mathrm{T}$-cell responses, and may significantly contribute to the recovery from COVID-19 [1].

In addition, inactivated and live attenuated vaccine platforms can induce broad and strong immune responses, in comparison to the other platforms, because they have the whole virion including structural and nonstructural proteins $[1,79,80]$. According to the vaccine tracker reported by the World Health Organization, October 2021, nearly 300 vaccine candidates are currently under various phases of development. In total candidate vaccines, 194 and 123 are in clinical and preclinical phases, respectively, that are available at https://www.who.int/ publications $/ \mathrm{m} /$ item/draft-landscape-of-covid-19-candidate-vaccines. There are 10 platforms for COVID-19 vaccines including, PS, nonreplicating viral vector (VVnr), replicating viral vector (VVr), VVnr in combination with an antigen-presenting cell ( $\mathrm{VVnr}+\mathrm{APC}), \mathrm{VVr}$ in combination with an antigen-presenting cell ( $\mathrm{VVr}+$ APC), virus-like particle, inactivated virus, live attenuated virus, mRNA vaccine (RNA), and DNA [30, 81, 82]. Around 11 vaccine candidates have been authorized/approved up to now in clinics and markets worldwide. Additionally, their platforms, clinical phase, manufacturing, and dosage are shown in Table 3 and Figure 5.

\section{Conclusion}

The pandemic of the newly identified coronavirus that is also known as COVID-19 is the third highly pathogenic human coronavirus. SARS-CoV-2 has less mortality than SARS-CoV-1 and MERS, but it has spread fast all over the world and has been declared a public health 


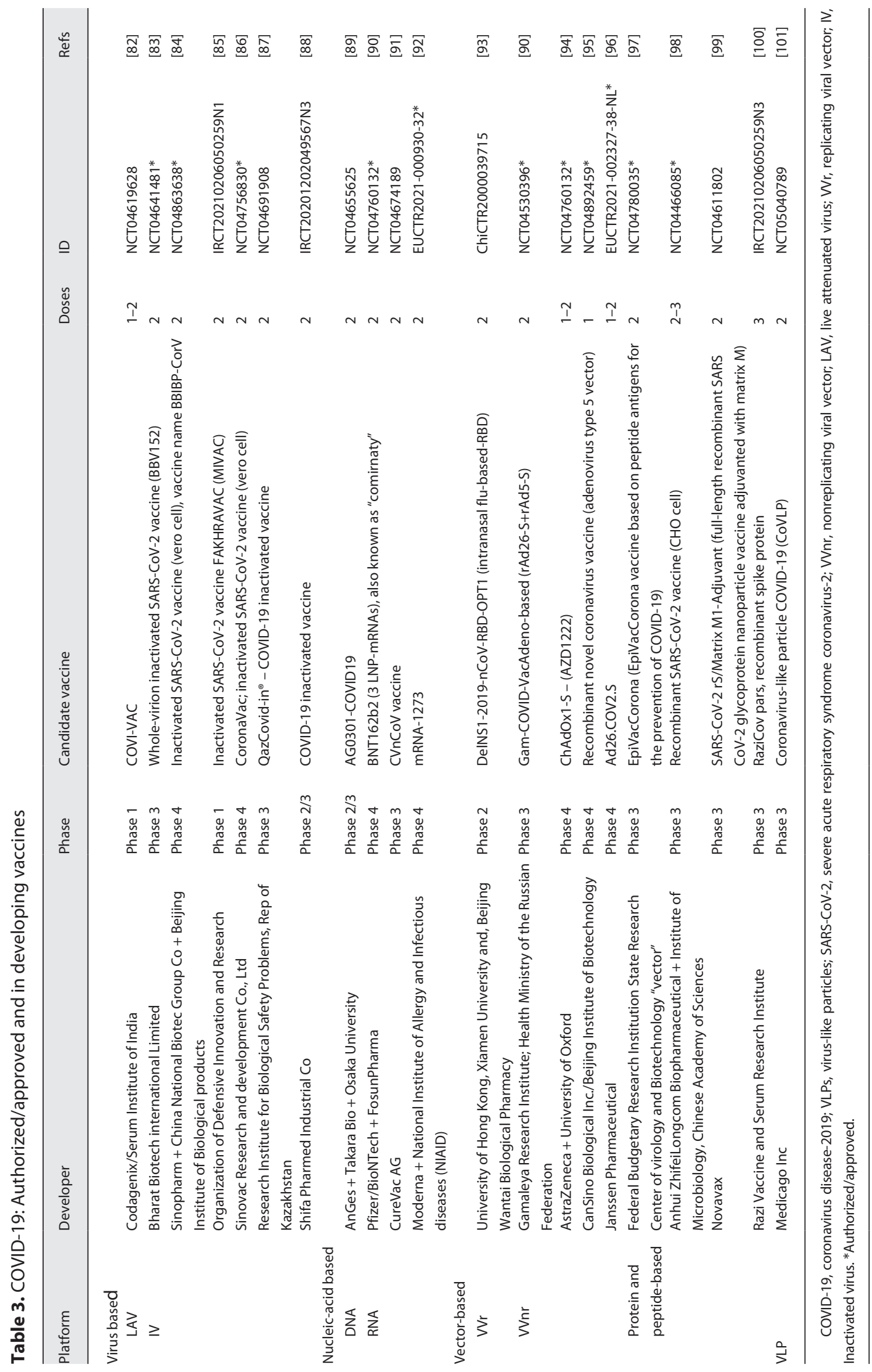




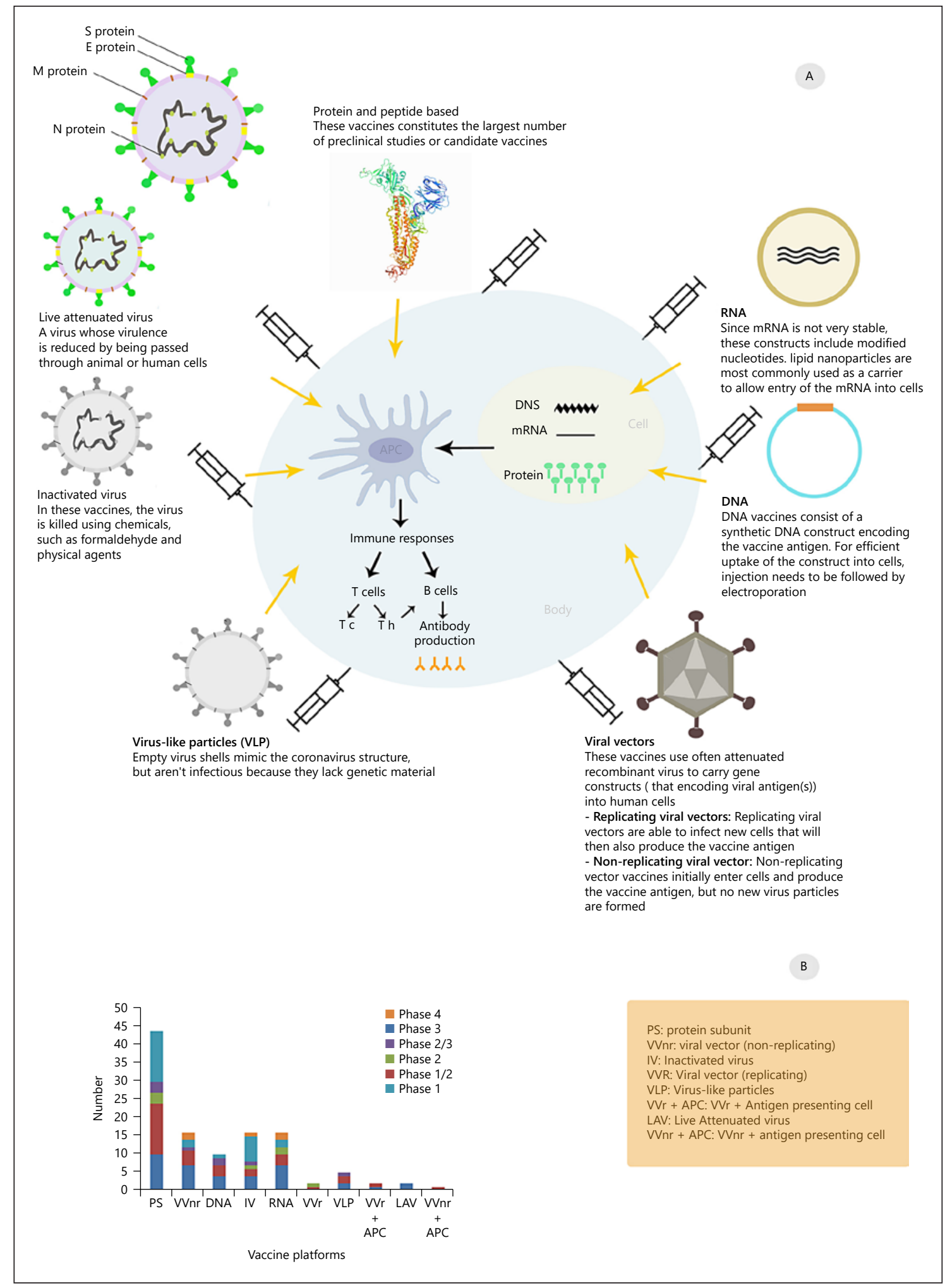

Fig. 5. Vaccines platforms against COVID-19. A Different vaccine platforms such as PS, VVnr, VVr, VLP, IV, LAV, mRNA (RNA), and DNA (DNA) vaccines can be considered to protect individuals, resulting in the reduction of the disease spread. B Distribution of approved and ongoing platforms in different clinical phases. COVID-19, coronavirus disease-2019; VLP, virus like particle; PS, protein subunit; IV, inactivated virus; VVnr, nonreplicating viral vector; LAV, live attenuated virus; VVr, replicating viral vector. 
emergency of international concern by the WHO. Despite extensive research and a flood of articles published daily on SARS-CoV-2, and advances in effective management of COVID-19, we will require in-depth studies about SARS-COV-2 pathogenesis. For the discovery of an effective drugs and vaccines against SARS-CoV-2, identification and evaluation of the available data on different molecular and cellular mechanisms involved in SARS$\mathrm{CoV}-2$ pathogenesis is very promising.

\section{Acknowledgment}

We are grateful to all the colleagues for critical reviews of the manuscript.

\section{Funding Sources}

No funding was received for this study. The authors declare no conflicts of interests.

\section{Author Contributions}

Ayyoob Khosravi designed and supervised the study with the help of Abasalt Hosseinzadeh Colagar. Ali Fallah wrote the first draft of the manuscript with support from Azadeh MohammadHasani. Parts of the manuscript were also written by Hadi Razavi Nikoo and Hamidreza Abbasi. Hamidreza Abbasi designed the figures and tables with the help of Ali Fallah. Ayyoob Khosravi, Hadi Razavi Nikoo, and Abasalt Hosseinzadeh Colagar participated in the final editing the manuscript. Hamidreza Abbasi played the main role in the submission of the manuscript. All authors give final approval of the manuscript to be submitted.

\section{Conflict of Interest Statement}

The authors declare that no conflict of interest exists.

\section{References}

1 Zhu N, Zhang D, Wang W, Li X, Yang B, Song $\mathrm{J}$, et al. A novel coronavirus from patients with pneumonia in China, 2019. N Engl J Med. 2020;382:727-33.

2 World Health Organization. Coronavirus disease 2019 (COVID-19): situation report, 73; 2020.

3 Perlman S. Another decade, another coronavirus. N Engl J Med. 2020;382:760-2.

4 Tang X, Wu C, Li X, Song Y, Yao X, Wu X, et al. On the origin and continuing evolution of SARS-CoV-2. Natl Sci Rev. 2020;7(6):101223.

5 Bian H, Zheng ZH, Wei D, Zhang Z, Kang WZ, Hao CQ, et al. Meplazumab treats COVID-19 pneumonia: an open-labelled, concurrent controlled add-on clinical trial. MedRxiv; 2020.

6 Liu Y, Gayle AA, Wilder-Smith A, Rocklöv J. The reproductive number of COVID-19 is higher compared to SARS coronavirus. J Travel Med. 2020;27(2):taaa021.

7 Ozma MA, Maroufi P, Khodadadi E, Köse Ş, Esposito I, Ganbarov K, et al. Clinical manifestation, diagnosis, prevention and control of SARS-CoV-2 (COVID-19) during the outbreak period. Infez Med. 2020;28(2): 153-65.

8 Habashi NM, Camporota L, Gatto LA, Nieman G. Functional pathophysiology of SARS$\mathrm{CoV}$-2-induced acute lung injury and clinical implications. J Appl Physiol. 2021;130(3): 877-91.

9 Prasad S, Potdar V, Cherian S, Abraham P, Basu A. Transmission electron microscopy imaging of SARS-CoV-2. Indian J Med Res. 2020;151(2-3):241.
10 El Jamal SM, Salib C, Stock A, Uriarte-Haparnas NI, Glicksberg BS, Teruya-Feldstein J, et al. Atypical lymphocyte morphology in SARS-CoV-2 infection. Pathol Res Pract. 2020;216(9):153063

11 Wu A, Peng Y, Huang B, Ding X, Wang X, Niu $P$, et al. Genome composition and divergence of the novel coronavirus (2019-nCoV) originating in China. Cell Host Microbe. 2020;27(3):325-8.

12 Rabaan AA, Al-Ahmed SH, Haque S, Sah R, Tiwari R, Malik YS, et al. SARS-CoV-2, SARS$\mathrm{CoV}$, and MERS-COV: a comparative overview. Infez Med. 2020;28(2):174-84.

13 Koyama T, Platt D, Parida L. Variant analysis of SARS-CoV-2 genomes. Bull World Health Organ. 2020;98(7):495.

14 Fehr AR, Perlman S. Coronaviruses: an overview of their replication and pathogenesis. Methods Mol Biol. 2015;1282:1-23.

15 Elaswad A, Fawzy M, Basiouni S, Shehata AA. Mutational spectra of SARS-CoV-2 isolated from animals. PeerJ. 2020;8:e10609.

16 Awadasseid A, Wu Y, Tanaka Y, Zhang W. SARS-CoV-2 variants evolved during the early stage of the pandemic and effects of mutations on adaptation in Wuhan populations. Int J Biol Sci. 2021;17(1):97.

17 Gorkhali R, Koirala P, Rijal S, Mainali A, Baral A, Bhattarai HK. Structure and function of major SARS-CoV-2 and SARS-CoV proteins. Bioinform Biol Insights. 2021; 15: 11779322211025876.

18 Yoshimoto FK. The proteins of severe acute respiratory syndrome coronavirus-2 (SARS CoV-2 or n-COV19), the cause of COVID-19. Protein J. 2020;39(3):198-216.
19 Yadav R, Chaudhary JK, Jain N, Chaudhary PK, Khanra S, Dhamija P, et al. Role of structural and non-structural proteins and therapeutic targets of SARS-CoV-2 for COVID-19. Cells. 2021;10(4):821.

20 Mariano G, Farthing RJ, Lale-Farjat SLM, Bergeron JRC. Structural characterization of SARS-CoV-2: where we are, and where we need to be. Front Mol Biosci. 2020;7:344.

21 Evans N, Martinez E, Petrosillo N, Nichols J, Islam E, Pruitt K, et al. SARS-CoV-2 and human immunodeficiency virus: Pathogen pincer attack. HIV/AIDS. 2021;13:361.

22 Ramírez Hernández E, Hernández-Zimbrón LF, Martínez Zúñiga N, Leal-García JJ, Ignacio Hernández V, Ucharima-Corona LE, et al. The role of the SARS-CoV-2 S-protein glycosylation in the interaction of SARS-CoV-2/ ACE2 and immunological responses. Viral Immunol. 2021;34(3):165-73.

23 Hoffmann M, Kleine-Weber H, Schroeder S, Krüger N, Herrler T, Erichsen S, et al. SARS-CoV-2 cell entry depends on ACE2 and TMPRSS2 and is blocked by a clinically proven protease inhibitor. cell. 2020;181(2): 271-e8.

24 Ji W, Wang W, Zhao X, Zai J. Homologous recombination within the spike glycoprotein of the newly identified coronavirus may boost cross-species transmission from snake to human. J Med Virol. 2020;92.

25 Ibrahim IM, Abdelmalek DH, Elshahat ME, Elfiky AA. COVID-19 spike-host cell receptor GRP78 binding site prediction. J Infect. 2020;80(5):554-62.

26 https://www.covid19treatmentguidelines. nih.gov. 
27 Mouffouk C, Mouffouk S, Mouffouk S, Hambaba L, Haba H. Flavonols as potential antiviral drugs targeting SARS-CoV-2 proteases (3CLpro and PLpro), spike protein, RNA-dependent RNA polymerase (RdRp) and angiotensin-converting enzyme II receptor (ACE2). Eur J Pharmacol. 2021;891: 173759.

28 Sternberg A, McKee DL, Naujokat C. Novel drugs targeting the SARS-CoV-2/COVID-19 machinery. Curr Top Med Chem. 2020; 20(16):1423-33.

29 Shi F, Wu T, Zhu X, Ge Y, Zeng X, Chi Y, et al. Association of viral load with serum biomakers among COVID-19 cases. Virology. 2020;546:122-6.

30 Taziki Balajelini MH, Rajabi A, Mohammadi M, Nikoo HR, Tabarraei A, Mansouri M, et al. Virus load and incidence of olfactory, gustatory, respiratory, gastrointestinal disorders in COVID-19 patients: A retrospective cohort study. Clin Otolaryngol. 2021;46(6):1331-8.

31 Valle C, Martin B, Touret F, Shannon A, Canard B, Guillemot JC, et al. Drugs against SARS-CoV-2: What do we know about their mode of action? Rev Med Virol. 2020;30(6): $1-10$.

32 Arumugham V. Immunological mechanisms explaining the role of IgE, mast cells, histamine, elevating ferritin, IL-6, D-dimer, VEGF levels in COVID-19 and dengue, potential treatments such as mast cell stabilizers, antihistamines, Vitamin C, hydroxychloroquine, ivermectin and azithromycin. Zenodo; 2020.

33 Gonçalves K, Vasconcelos A, Barbirato D, Vasconcelos C, Vasconcelos B, et al. Therapeutic potential of ivermectin for COVID-19. Authorea Preprints; 2020.

34 Skipper CP, Pastick KA, Engen NW, Bangdiwala AS, Abassi M, Lofgren SM, et al. Hydroxychloroquine in nonhospitalized adults with early COVID-19: a randomized trial. Ann Intern Med. 2020;173(8):623-31.

35 Cortegiani A, Ingoglia G, Ippolito M, Giarratano A, Einav S. A systematic review on the efficacy and safety of chloroquine for the treatment of COVID-19. J Crit Care. 2020;57: 279-83.

36 Casadevall A, Pirofski LA. The convalescent sera option for containing COVID-19. J Clin Invest. 2020;130(4):1545-8.

37 Iwasaki A, Yang Y. The potential danger of suboptimal antibody responses in COVID-19. Nat Rev Immunol. 2020;20(6):339-41.

38 Brown BL, McCullough J. Treatment for emerging viruses: convalescent plasma and COVID-19. Transfus Apher Sci. 2020;59(3): 102790.

39 Salazar E, Perez KK, Ashraf M, Chen J, Castillo B, Christensen PA, et al. Treatment of COVID-19 patients with convalescent plasma in Houston, Texas. Am J Pathol. 2020.

$40 \mathrm{Lv}$ L, Zhang L. Host proviral and antiviral factors for SARS-CoV-2. Virus genes. 2021:114.

41 Sun Y, Xue F, Guo Y, Ma M, Hao N, Zhang $\mathrm{XC}$, et al. Crystal structure of porcine repro- ductive and respiratory syndrome virus leader protease Nsp1alpha. J Virol. 2009;83(21): 10931-40.

42 Ziv O, Price J, Shalamova L, Kamenova T, Goodfellow I, Weber F, et al. The short- and long-range RNA-RNA interactome of SARSCoV-2. Mol Cell. 2020;80(6):1067-77.

43 Santos-Beneit F, Raškevičius V, Skeberdis VA, Bordel S. A metabolic modeling approach reveals promising therapeutic targets and antiviral drugs to combat COVID-19. Sci Rep. 2021;11(1):11982-11.

44 Kumar S, Nyodu R, Maurya VK, Saxena SK. Morphology, genome organization, replication, and pathogenesis of severe acute respiratory syndrome coronavirus 2 (SARS-CoV-2). Coronavirus Disease 2019 (COVID-19). 2020:23.

45 Bosch-Barrera J, Martin-Castillo B, Buxó M, Brunet J, Encinar JA, Menendez JA. Silibinin and SARS-CoV-2: dual targeting of host cytokine storm and virus replication machinery for clinical management of COVID-19 patients. J Clin Med. 2020;9(6):1770.

46 Gul S, Ozcan O, Asar S, Okyar A, Barıs I, Kavakli IH. In silico identification of widely used and well-tolerated drugs as potential SARSCoV-2 3C-like protease and viral RNA-dependent RNA polymerase inhibitors for direct use in clinical trials. J Biomol Struct Dyn. 2021;39(17):6772-91.

47 Noor R. Antiviral drugs against severe acute respiratory syndrome coronavirus 2 infection triggering the coronavirus disease-19 pandemic. Tzu Chi Med J. 2021 Jan-Mar;33(1):7.

48 Dhama K, Khan S, Tiwari R, Sircar S, Bhat S, Malik YS, et al. Coronavirus disease 2019-COVID-19. Clin Microbiol Rev. 2020;33(4): e00028-20.

49 Arya R, Das A, Prashar V, Kumar M. Potential inhibitors against papain-like protease of novel coronavirus (COVID-19) from FDA approved drugs. ChemRxiv; 2020

50 Li X, Geng M, Peng Y, Meng L, Lu S. Molecular immune pathogenesis and diagnosis of COVID-19. J Pharm Anal. 2020;10(2):102-8.

51 Feng J, et al. Novel insights into the pathogenesis of virus-induced ARDS: review on the central role of the epithelial-endothelial barrier. Expert Review of Clinical Immunology. 2021:1-11.

52 Alijotas-Reig J, Esteve-Valverde E, Belizna C, Selva-O'Callaghan A, Pardos-Gea J, Quintana A, et al. Immunomodulatory therapy for the management of severe $\mathrm{CO}$ VID-19. Beyond the anti-viral therapy: a comprehensive review. Autoimmun Rev. 2020;19(7):102569.

53 Asrani P, Hassan MI. SARS-CoV-2 mediated lung inflammatory responses in host: targeting the cytokine storm for therapeutic interventions. Mol Cell Biochem. 2021;476(2): 675-87.

54 Burrage DR, Koushesh S, Sofat N. Immunomodulatory drugs in the management of SARS-CoV-2. Front Immunol. 2020;11: 1844.
55 Huang C, Wang Y, Li X, Ren L, Zhao J, Hu Y, et al. Clinical features of patients infected with 2019 novel coronavirus in Wuhan, China. Lancet. 2020;395(10223):497-506.

56 Taghizadeh P, Salehi S, Heshmati A, Houshmand SM, InanlooRahatloo K, Mahjoubi F, et al. Study on SARS-CoV-2 strains in Iran reveals potential contribution of co-infection with and recombination between different strains to the emergence of new strains. Virology. 2021;562:63-73.

57 Sah P, Fitzpatrick MC, Zimmer CF, Abdollahi E, Juden-Kelly L, Moghadas SM, et al. Asymptomatic SARS-CoV-2 infection: a systematic review and meta-analysis. Proc Natl Acad Sci. 2021;118(34):e2109229118.

58 Tang YW, Schmitz JE, Persing DH, Stratton CW. Laboratory diagnosis of COVID-19: current issues and challenges. J Clin Microbiol. 2020;58(6):e00512-20.

59 Cheraghali F, Tahamtan A, Hosseini SA, Gharib MH, Moradi A, Razavi Nikoo H, et al. Case report: detection of SARS-CoV-2 from cerebrospinal fluid in a 34-month-old child with encephalitis. Front Pediatr. 2021;9:194.

60 Kitane DL, Loukman S, Marchoudi N, Fernandez-Galiana A, El Ansari FZ, Jouali F, et al. A simple and fast spectroscopy-based technique for Covid-19 diagnosis. Sci Rep. 2021; 11(1):16740-11.

61 Bahmani MK, Khosravi A, Miri R, Iwabu Y, Ikuta K, Sakudo A. Spectroscopic characterization of human immunodeficiency virus type-1-infected plasma by principal component analysis and soft independent modeling of class analogy of visible and near-infrared spectra. Mol Med Rep. 2009;2(5):805-9.

62 Wyllie AL, Fournier J, Casanovas-Massana A, Campbell M, Tokuyama M, Vijayakumar P, et al. Saliva is more sensitive for SARS-CoV-2 detection in COVID-19 patients than nasopharyngeal swabs. MedRxiv; 2020.

63 Abbasi H, Tabaraei A, Hosseini SM, Khosravi A, Nikoo HR. Real-time PCR Ct value in SARS-CoV-2 detection: RdRp or N gene? Infection. 2021:1-4.

64 Mei Y, Weinberg SE, Zhao L, Frink A, Qi C, Behdad A, et al. Risk stratification of hospitalized COVID-19 patients through comparative studies of laboratory results with influenza. EClinicalMedicine. 2020;26: 100475.

65 Rodriguez-Morales AJ, Cardona-Ospina JA, Gutiérrez-Ocampo E, Villamizar-Peña R, Holguin-Rivera Y, Escalera-Antezana JP, et al. Clinical, laboratory and imaging features of COVID-19: a systematic review and metaanalysis. Travel Med Infect Dis. 2020;34: 101623.

66 Sanyaolu A, Okorie C, Marinkovic A, Patidar $\mathrm{R}$, Younis K, Desai P, et al. Comorbidity and its impact on patients with COVID-19. SN Compr Clin Med. 2020:1-8.

67 Goldstein E, Lipsitch M, Cevik M. On the effect of age on the transmission of SARSCoV-2 in households, schools, and the community. J Infect Dis. 2021;223(3):362-9. 
68 Hyde Z. Difference in SARS-CoV-2 attack rate between children and adults may reflect bias. Clin Infect Dis. 2021:ciab183.

69 Kuppusamy M, Loganathan S, Wankhar W, Gurugubelli KR, Mahadevappa VH, Lepcha $\mathrm{L}$, et al. Angiotensin-converting enzyme 2 (ACE2): COVID 19 gate way to multiple organ failure syndromes. Respir Physiol Neurobiol. 2021;283:103548.

70 Preskorn SH. The $5 \%$ of the population at high risk for severe COVID-19 infection is identifiable and needs to be taken into account when reopening the economy. J Psychiatric Prac. 2020;26:219-27.

71 Bilich T, Nelde A, Heitmann JS, Maringer Y, Roerden M, Bauer J, et al. T cell and antibody kinetics delineate SARS-CoV-2 peptides mediating long-term immune responses in $\mathrm{CO}$ VID-19 convalescent individuals. Sci Transl Med. 2021;13(590):eabf7517.

72 Wrapp D, Wang N, Corbett KS, Goldsmith JA, Hsieh CL, Abiona O, et al. Cryo-EM structure of the 2019-nCoV spike in the prefusion conformation. Science. 2020;367(6483):1260-3.

73 Liu R, Moise L, Tassone R, Gutierrez AH, Terry FE, Sangare K, et al. H7N9 T-cell epitopes that mimic human sequences are less immunogenic and may induce Treg-mediated tolerance. Hum Vaccin Immunother. 2015; 11(9):2241-52.

74 Wu Y, Li C, Xia S, Tian X, Kong Y, Wang Z, et al. Identification of human single-domain antibodies against SARS-CoV-2. Cell Host Microbe. 2020;27(6):891-e5.
75 Gangadevi S, Badavath VN, Thakur A, Yin N, De Jonghe $\mathrm{S}$, Acevedo $\mathrm{O}$, et al. Kobophenol a inhibits binding of host ace2 receptor with spike rbd domain of sars-cov-2, a lead compound for blocking covid-19. J Phys Chem Lett. 2021;12(7):1793-802.

76 Kalathiya U, Padariya M, Mayordomo M, Lisowska M, Nicholson J, Singh A, et al. Highly conserved homotrimer cavity formed by the SARS-CoV-2 spike glycoprotein: a novel binding site. J Clin Med. 2020;9(5):1473.

77 Callaway $\mathrm{E}$. The race for coronavirus vaccines: a graphical guide. Nature. 2020;580: 576-7.

78 Jiang S, He Y, Liu S. SARS vaccine development. Emerg Infect Dis. 2005;11(7):1016.

79 Ndwandwe D, Wiysonge CS. COVID-19 vaccines. Curr Opin Immunol. 2021;71:111-6.

80 van Riel D, de Wit E. Next-generation vaccine platforms for COVID-19. Nat Mater. 2020;19(8):810-2.

81 World Health Organization. Draft landscape of COVID-19 candidate vaccines: WHO. 2021. Available from: https://www.who.int/ publications/m/item/draft-landscape-of-covid-19-candidate-vaccines.

82 https://clinicaltrials.gov/ct2/show/ NCT04619628

83 https://clinicaltrials.gov/ct2/show/ NCT04641481.
84 https://clinicaltrials.gov/ct2/show/ NCT04863638.

85 https://www.irct.ir/trial/54133.

$86 \mathrm{https} / / /$ clinicaltrials.gov/ct2/show/ NCT04756830.

87 https://clinicaltrials.gov/ct2/show/ NCT04691908.

88 https://www.irct.ir/trial/54881.

89 https://clinicaltrials.gov/ct2/show/ NCT04655625.

90 https://clinicaltrials.gov/ct2/show/ NCT04760132.

$91 \mathrm{https} / /$ clinicaltrials.gov/ct2/show/ NCT04674189.

$92 \mathrm{https} / / / \mathrm{www} . c l i n i c a l t r i a l s r e g i s t e r . e u / c t r-$ search/trial/2021-000930-32/BE.

$93 \mathrm{http} / / /$ www.chictr.org.cn/historyversionpuben.aspx?regno $=$ ChiCTR2000039715.

$94 \mathrm{https} / / /$ clinicaltrials.gov/ct2/show/ NCT04530396.

95 https://clinicaltrials.gov/ct2/show/ NCT04892459.

96 https://www.clinicaltrialsregister.eu/ctrsearch/trial/2021-002327-38/NL

$97 \mathrm{https} / / /$ clinicaltrials.gov/ct2/show/ NCT04780035.

98 https://clinicaltrials.gov/ct2/show/ NCT04466085

99 https://clinicaltrials.gov/ct2/show/ NCT04611802.

100 https://en.irct.ir/trial/57980.

$101 \mathrm{https} / /$ clinicaltrials.gov/ct2/show/ NCT05040789. 